\section{International Scientific Journal Theoretical \& Applied Science}

p-ISSN: $2308-4944$ (print)

e-ISSN: 2409-0085 (online)

Year: $2014 \quad$ Issue: $11 \quad$ Volume: 19

Published: $30.11 .2014 \quad \underline{\text { http://www.T-Science.org }}$

SECTION 19. Management. Marketing. Public administration.
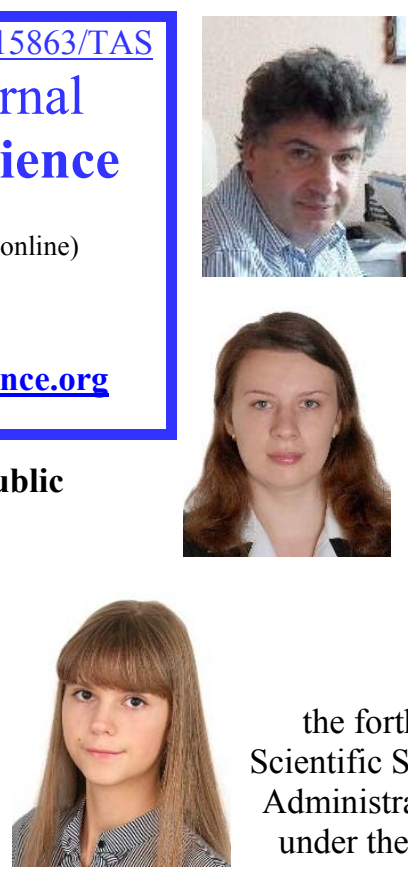

Andrei Olegovich Blinov

Doctor of Economic Sciences, professor of "General Management" department at the Financial University under the Government of the Russian Federation, Russia aoblinov@mail.ru

Marina Konstantinovna Krivtsova the forth-year student, the Chairman of Scientific Student Society of Public and Municipal Administration faculty at the Financial University under the Government of the Russian Federation marinstar@bk.ru

Maria Aleksandrovna Podzorova the forth-year student, the Deputy Chairman of Scientific Student Society of Public and Municipal Administration faculty at the Financial University under the Government of the Russian Federation marusia15@inbox.ru

\title{
MANAGEMENT CONSULTING AS AN INSTITUTE OF INCREASING MANAGEMENT EFFICIENCY OF THE ORGANIZATIONS IN MODERN CONDITIONS
}

Abstract: In this article the problem of increasing management efficiency of the organizations in modern conditions is considered, the role of administrative consulting in this process is emphasized as well. On the basis of the analysis of functions and problems of administrative consultation the authors touch upon the factors which influence on an increase of its productivity for a consulting organization.

Key words: management consulting, efficiency, functions, administrative consultation, tasks, organization.

Language: Russian

Citation: Blinov AO, Krivtsova MK, Podzorova MA (2014) MANAGEMENT CONSULTING AS AN INSTITUTE OF INCREASING MANAGEMENT EFFICIENCY OF THE ORGANIZATIONS IN MODERN CONDITIONS. ISJ Theoretical \& Applied Science 11 (19): 11-15. http://dx.doi.org/10.15863/TAS.2014.11.19.3

\section{УПРАВЛЕНЧЕСКОЕ КОНСУЛЬТИРОВАНИЕ КАК ИНСТИТУТ ПОВЫШЕНИЯ ЭФФЕКТИВНОСТИ УПРАВЛЕНИЯ ОРГАНИЗАЦИЯМИ В СОВРЕМЕННЫХ УСЛОВИЯХ}

Аннотация: В данной статье рассматривается проблема повышения эффективности управления организациями в современных условиях, подчеркивается роль управленческого консалтинга в данном прочессе. На основе анализа функций и задач управленческого консультирования, авторы приводят факторы, влияющие на повышение его результативности для консультационной организации.

Ключевые слова: управленческий консалтинг, эффективность, функции, управленческое консультирование, задачи, организация.

Усложняющиеся условия современного управления требуют постоянного развития теоретических концепций управления и прикладных управленческих технологий. Носителями новых теоретических и прикладных знаний по проблемам управления становятся специалисты по управленческому консультированию, которые играют все более значительную роль в управленческом процессе. Управленческое консультирование как особое направление профессиональной деятельности представляет собой экспертную помощь со стороны специалистов по управлению и призвано на основе научного анализа конкретных производственных ситуаций выработать наиболее приемлемые пути повышения эффективности работы предприятия и способы их внедрения, используя достижения современной управленческой науки. 
Преимущество консультантов по управлению перед управленцами состоит в независимости и непредвзятости взглядов, в более широком кругозоре. Они обладают обширной информацией в самых различных областях управления и хозяйствования (в силу меньшей загруженности проблемами текущего управления), ориентируются на широкое изучение проблемы и перенос опыта других организаций (в основном это касается внешних консультантов) [2, с. 91].

Чаще всего организации прибегают к помощи консультантов для развития своего собственного потенциала или консультант привлекается в качестве «узкого» специалиста в определенной сфере для решения возникших проблем. Растущая сложность и увеличивающийся темп общих экономических изменений, условий ведения бизнеса порождают специфические проблемы, при решении которых все чаще и чаще предприятия испытывают необходимость в помощи консультантов.

Следует отметить, что в процессе построения отношений между консультантом и клиентом также возможно зарождение проблем, поскольку такие отношения неустойчивы, имеет место динамика не только довериянедоверия, пониманиянепонимания, но и динамика интересов как краткосрочных, так и долгосрочных. Как только начинается «перетягивание одеяла на себя», неучет интересов клиента консультантом или наоборот, поскольку фактически клиент далеко не всегда прав, то отношения входят в зону неустойчивости, разбалансировки, что требует дополнительных управленческих усилий.

Можно утверждать, что в процессе работы с клиентом консультант сталкивается с двумя видами проблем:

1. Проблемы первого рода - проблемы, которые являются предметом его профессионального исследования и разработки предложений по их разрешению, т. е. консалтинга.

2. Проблемы второго рода - проблемы, которые возникают в процессе консалтинга при взаимодействии с клиентом.

Понятно, что проблемы второго рода во многом зависят от того, насколько эффективно решаются проблемы первого рода, а решение проблем первого рода в основном зависит от профессионализма консультанта, тем не менее можно выделить еще ряд факторов, таких как степень совпадения культуры консультанта и клиента, цель (намерение), с которой клиент приглашает консультанта, а также степень удовлетворения ожиданий консультанта и клиента [1, с. 145].
Зарождение

управленческого консультирования было вызвано постоянным поиском предпринимателями новых средств повышения эффективности производства, попытками со стороны специалистов управления найти коммерческое приложение своим способностям, логикой развития организационной науки и практики.

Имеетя множество определений управленческого консультирования. Можно выделить два основных подхода к консультированию.

В первом случае используется широкий функциональный взгляд на консультирование. Фриц Стееле определяет его так: «Под процессом консультирования я понимаю любую форму оказания помощи в отношении содержания, процесса или структуры задачи или серии задач, при которой консультант сам не отвечает за выполнение задачи, но помогает тем, кто ответствен за это».

Второй подход рассматривает консультирование как особую профессиональную службу и выделяет ряд характеристик, которыми она должна обладать. Согласно Лэрри Грейнеру и Роберту Метцгеру «управленческое консультирование - это консультативная служба, работающая по контракту и оказывающая услуги организациям с помощью специально обученных и квалифицированных лиц, которые помогают организации-заказчику выявить управленческие проблемы, проанализировать их, дают рекомендации по решению этих проблем и содействуют, при необходимости, выполнению решений». Можно считать два эти подхода взаимодополняющими.

В частности, Европейская Федерация ассоциаций консультантов по экономике и управлению (ФЕАКО) дает следующее определение: «Менеджмент-консалтинг заключается в предоставлении независимых советов и помощи по вопросам управления, включая определение и оценку проблем и/или возможностей, рекомендацию соответствующих мер и помощь в их реализации». Такого же определения придерживается Американская Ассоциация консультантов по экономике и управлению (АСMЕ) и Институт менеджментконсультантов (IMC) [5, с. 30].

Анализ представленных формулировок не дает оснований взять какую-либо из них за образец, поскольку каждая из них фиксирует лишь определенную сторону консалтинговой деятельности. Поэтому симбиоз формулировок консалтинговой деятельности как специфической формы деятельности может дать более полное и более системное определение. 
В результате целесообразно использовать следующее определение консалтинговой деятельности (рис. 1).
Вид интеллектуальной профессиональной деятельности, в процессе которого квалифицированный консультант предоставляет объективные и независимые советы, способствующие успешному управлению организацией-клиентом.

\section{Рисунок 1 - Сущность менеджмент-консалтинга.}

Управленческое консультирование как вид деятельности в настоящее время в России находится на стадии институциализации, а как вид бизнеса составляет значительный сегмент рынка деловых услуг, обнаруживающий тенденцию к расширению спроса и предложения и повышению капиталоемкости, что отражает потребность общества в повышении эффективности управления, конкурентноспособности отечественных бизнесорганизаций, ответом на вызовы современного рыночного хозяйства, процессы глобализации. Все это порождает необходимость теоретической и методологической рефлексии современной практики управленческого консультирования.

Для управленческого консалтинга характерна тесная связь со смежными видами бизнеса (юридическим консультированием, аудитом, установкой и обслуживанием информационных систем и др.); хотя внутри управленческого консультирования как вида деятельности отмечается тенденция, к большей специализации, прослеживается вполне определенная тенденция к универсализации консалтинговых компаний с целью формирования полного пакета консалтинговых услуг, благодаря чему достигается цель комплексного обслуживания клиента и установления с ним долговременного сотрудничества. Однако, с учетом восприятия клиента, эта универсализация нередко принимает вид диверсификации. С чисто маркетинговыми целями универсальная услуга позиционируется как специфическая, ориентированная на конкретный бизнес [4, с. 165].

Разнообразие

применяемых в консультационной деятельности моделей, подходов, методов, технологий обусловлено стремлением к широкому применению накопленного опыта, экономии времени и ресурсов при выполнении повторяющихся работ, желанием быстро и качественно решать задачи и проблемы клиентской организации с использованием интеллектуального потенциала работников. От того, насколько процесс консультирования предполагает совместную деятельность руководителей и специалистов предприятия с консультантом, зависит качество ожидаемых изменений, степень достижения необходимых предприятию результатов, эффективность использования задействованных ресурсов и, в конечном итоге, успешность сотрудничества сторон. В практике консультационной деятельности сложилось несколько базовых моделей, отражающих специфику клиент-консультантских взаимодействия: экспертное консультирование, консультирование по проекту, консультирование по процессу, обучающее консультирование. Ocобое место занимают методы организационного развития - эти методы направлены на изменения в поведении работников через воздействие на систему ценностных ориентации, межличностное и межгрупповое воздействие, индивидуальное навыки, создание условий для более интенсивного использования человеческих ресурсов. В современной консультационной практике все большее место занимают комплексные методы, направленные на комплексное решение проблем клиентских организаций. Множественность методов осложняет задачу выбора тех из них, которые позволяют наиболее эффективно решить управленческие проблемы. Консультантам приходится анализировать, в каждом конкретном случае, большое количество факторов, учитывать многообразные специфические условия клиентской организации.

Одной из важных стратегических функций управленческого консалтинга является то, что он служит распространению мировых стандартов эффективного менеджмента и тем самым 
способствует глобализации бизнеса, его интернационализации.

Этим обусловлена позитивная роль управленческого консультирования в экономике России на современном этапе ее развития. Помощь внешних консультантов, как зарубежных, так и российских, позволяет российскому менеджеру не только повысить эффективность своего бизнеса, но, что на сегодняшнем этапе еще важнее, привести его в соответствие с мировыми стандартами корпоративного менеджмента, сделать его более транспарентным и тем самым более привлекательным для стратегических инвесторов.

Управленческое консультирование осуществляет целый ряд функций (рис. 2).

\section{Функции управленческого консультирования}

\begin{tabular}{|c|}
\hline Функции управленческого консультирования \\
\hline $\begin{array}{l}\text { 1. Консультационное обследование, или управленческий аудит: консультант изучает ресурсы компании, } \\
\text { результаты ее деятельности, управленческую политику с целью определения ее сильных и слабых сторон } \\
\text { и ключевых проблем. В большинстве случаев такое обследование осуществляется на первой стадии } \\
\text { консультирования, но иногда оно может быть и отдельным консалтинговым проектом; }\end{array}$ \\
\hline $\begin{array}{l}\text { 2. Специальные исследования и обзоры. Такие исследования проводятся консультантами в любой области } \\
\text { менеджмента. Например, исследования возможностей для будущих инвестиций, изучение возможностей } \\
\text { рынка, исследование отношений потребителей к продукции компании и т.п.; }\end{array}$ \\
\hline $\begin{array}{l}\text { 3. Разработка решений по определенным проблемам. В данном случае клиент хочет получить помощь } \\
\text { большую, чем просто исследование его проблем. Примеры таких заданий: разработка проекта новой } \\
\text { организационной структуры, реорганизация информационной системы и т.П.; }\end{array}$ \\
\hline $\begin{array}{l}\text { 4. Помощь в реализации решения. Консультанта могут попросить остаться в организации на время } \\
\text { внедрения его предложения. Он может участвовать в этом процессе (например, в отборе и подготовке } \\
\text { кадров), а также помогать менеджеру убедить сотрудников в преимуществах новой системы; }\end{array}$ \\
\hline $\begin{array}{l}\text { 5. Выполнение функций эксперта. Высшие руководители многих фирм обращаются за экспертизой к } \\
\text { консультанту, прежде чем «запускать» новые проекты или представлять их совету директоров. }\end{array}$ \\
\hline
\end{tabular}

Рисунок 2 - Основные функции управленческого консультирования [5].

Главной задачей, решаемой консультантами по управлению является оптимизация системы управления предприятием, повышение её эффективности, что ставит, в свою очередь, проблему оценки эффективности управления в целом, определяет необходимость выявления критериев результативности управленческого консультирования, повышения его качества [2, с. $178]$.

Помимо данной задачи в процессе управленческого консалтинга может решаться самый широкий круг задач (рис. 3).

Эффективностью управленческого консультирования для консультационной организации являются: расширение рынка и объема услуг, рентабельность проекта, удельные затраты на маркетинг, структура издержек, выработка на одного консультанта, т. е повышения эффективности управления бизнес организации в целом. На эффективность консультационной деятельности позитивно влияет и сложившаяся инфраструктура регулирования и саморегулирования качества консалтинговых услуг. Рассмотренный фрагмент консультационного проекта показывает, что его успешность в значительной степени определятся богатством используемого консультантом инструментария и включенностью в процесс сотрудников клиентской организации. 


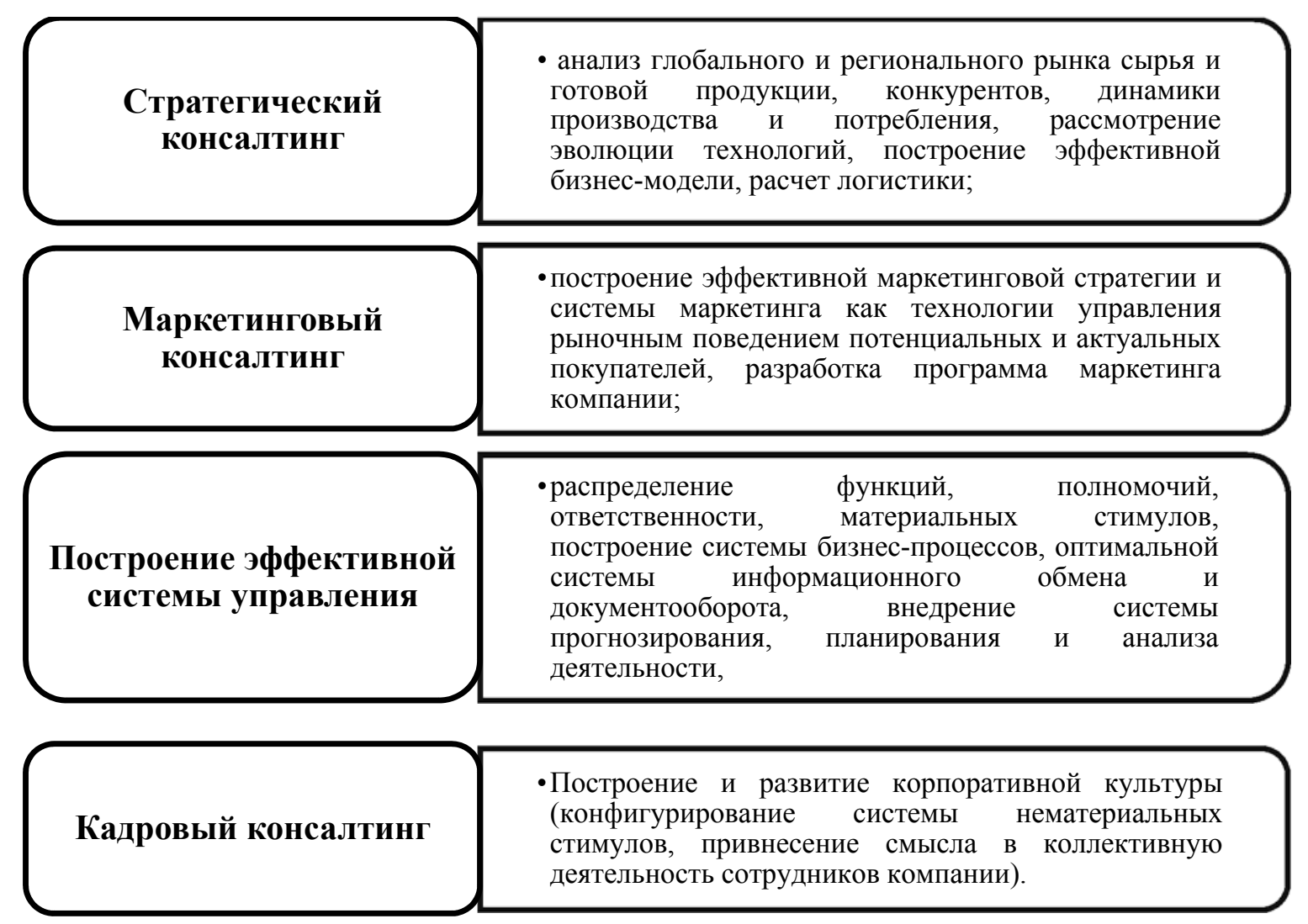

Рисунок 3 - Виды управленческого консалтинга по решаемым задачам.

Таким образом, дальнейшее развитие управленческого консультирования в России в целях повышения эффективности систем управления различными бизнес-организациями, применения современных управленческих технологий, улучшения инвестиционной привлекательности связано с усилением осознания значимости управленческого консультирования современными руководителями, ростом его востребованности.

\section{References:}

1. Blinov AO, Dresvyannikov VA (2013) Upravlencheskoe konsul'tirovanie. Uchebnik dlya magistrov. Moscow: Izdatel'skotorgovaya korporatsiya «Dashkov i $\mathrm{K}^{\circ} », 212$.

2. Gibson DJ, Ivantsevich DM, Donnelli-ml. DX (2012) Organizatsii: povedenie, struktura, protsessy. per. s angl. 8-e izd.- Moscow: INFRA-M, 662.

3. Efremov VS (2010) Upravlencheskiy konsalting kak biznes. Menedzhment v Rossii i za rubezhom. No. 5. pp. 70-79.

4. Kapustin PA (2011) Upravlencheskoe konsul'tirovanie dlya rukovoditeley.- $\mathrm{SPb}$.: «Izdatel'skiy dom «Biznes-pressa».

5. Komarov EI (2013) Organizatsionnye i dezorganizatsionnye metody upravleniya kak sostavlyayushchie organizatsionnoy i dezorganizatsionnoy kul'tury predpriyatiya. Upravlenie personalom. No. 11. pp.28- 33.
6. Kotlyarevskiy YJ (2010) Upravlencheskoe konsul'tirovanie v Rossii. Rostov-na-Donu : "Feniks", 352.

7. Kudinov A (2000) Vozmozhnosti upravlencheskogo konsul'tirovaniya. Konsul'tant direktora, No.4(112). pp.34-36

8. Mil'ner B (2012) Teoriya organizatsiy. Moscow.

9. Khokhlova T (2012) Stanovlenie i razvitie upravlencheskogo konsul'tirovaniya $\mathrm{v}$ Rossii. Problemy teorii i praktiki upravleniya. No.5. pp.113-118.

10. Shmakov VI (2012) Upravlenie kak sposob regulirovaniya slozhnykh sotsial'nykh sistem (organizatsiy). V kn. Vvedenie v sotsiologiyu: Materialy k lektsiyam. Moscow: Maks Press. 